\title{
Isla nerviosa: madness, psychiatry, and reform in nineteenth- and twentieth-century Cuba
}

\section{Isla nerviosa: loucura, psiquiatria e reforma em Cuba, séculos XIX e XX}

\author{
Julia Emilia Rodriguez ${ }^{i}$ \\ i Professor, College of Liberal Arts/University of New Hampshire. \\ Durham - NH - USA \\ orcid.org/0000-0001-5760-1024 \\ juliar@unh.edu
}

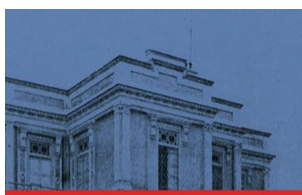

MADHOUSE

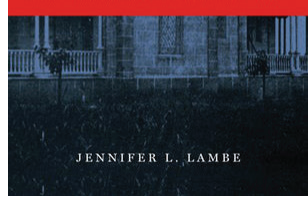

LAMBE, Jennifer L. Madhouse: psychiatry and politics in Cuban history. Chapel Hill: University of North Carolina Press. 2017. $325 p$.
This history of Cuba's main psychiatric asylum, Mazorra - named after the owner of the slave plantation upon which the hospital was built - aims to be much more. Impressive in scope, historical detail, and thoughtful analysis, Madhouse largely meets its two parallel, if overlapping goals: to trace the history of attitudes towards and the experience of mental illness in Cuba, and to introduce a set of new historically-informed concepts for understanding Cuban mental states. Lambe evokes the latter in a line on the very first page of the book's Introduction: "In the borderlands of indifference and on the margins of meaning lies Mazorra, primordial laboratory of the fifth dimension" (Lambe, 2017, p.1) The book fulfills the first goal well and provides a lot of insight into the second.

Lambe's goal is not just to reconstruct Cuba's attempts to deal with mental illness, but to understand the contours and effectiveness (or lack thereof) of the Cuban state through three or four very different eras. From the late nineteenth and early twentieth centuries, with its two US occupations, to the years of corruption, the Revolution, and beyond, Lambe documents the tremendous changes in the Cuban psych fields, as well as some continuities. The first sixty-plus years of Mazorra's existence were marred by brutal levels of neglect; the mid-twentieth century attempts at reform had minimal effect. After the revolution, the government harnessed the power of a strong, centralized state and clear sociological objectives to broaden and deepen the treatment of social pathologies. Throughout, Lambe argues, Mazorra remained an enduring symbol of the island, including its best and worst images.

Madhouse is framed by a number of themes, including historical memory, medicine and the state, the cultural history of madness, and the history of sexuality. The book is organized chronologically, beginning the Introduction with the construction of the island's first insane asylum on the grounds of the former Mazorra plantation in the 1850s. 
Chapter one discusses the effects of the United States occupation (1899-1902) and the first attempts to modernize the Cuban asylum according to US Progressivism. The anti-Spanish Cuban nationalism of professionals on the island lent extra weight to the North American leaders, who introduced new techniques and scientific approaches to nursing, hygiene, and work therapy. The next chapter explores ongoing attempts to fix the institution, including the introduction of theories of insanity and degeneration popular in Europe and the USA. In particular, these reformers focused on alcohol abuse as the supposed source of most mental pathologies in Cuba. Next, in chapter three, Lambe focuses on a major trend in early twentieth century Cuban culture: the medicalization of popular religious practices, in particular those of the island's many Afro-Cubans. Folk religions like Santería were stigmatized in the press and among medical and social science professionals. Meanwhile, despite the state pathologization of folk beliefs, Mazorra remained underfunded and neglected, characterized by the inmates' high death rates and abysmal conditions. Chapter four discusses the extreme corruption of the Cuban state in the 1930s and 1940s, which retarded Mazorra's chances for progress, despite the growing influence of medical professionals and the introduction of new treatments. This period also saw a growing articulation of homosexuality as a vice and pathology. In the end, however, continuity ruled the day, as Mazorra remained blighted by poor conditions and high death rates.

The last three chapters analyze the lasting impact of the 1959 revolution on the treatment of mental health. In chapter five we learn that one of Fidel Castro's first steps was to publicly announce an overhaul of Mazorra, which would serve as a symbol of the Revolution's commitment to cultivating human capital. In this period, the centrality of work therapy took on new meanings. Another distinction of this period is the extreme pathologization, even institutionalization, of homosexual men and women. Medical professionals debated whether undesirable sexualities could be "cured" or not, and placed stigmatized individuals in camps. Chapter six looks at investments in social science research that measured (and augmented) everyday Cubans' psychological responses to the revolution. Not surprisingly, the researchers found their respondents - but especially members of the working class - to have overall positive attitudes. Castro's state also created university departments of psychology, and gave them equal or greater power than psychiatrists and continued to idolize physical labor (in the sugar harvest, for example) as curative. Chapter seven follows the topic to southern Florida, that is, to participants in the late twentieth century Cuban diaspora. The Mariel Boatlift of 1980 raised complex issues not just about the state of Cuban mental health and its institutions, but also about US society. Mariel refugees arrived just as US mental hospitals were being dismantled. In addition, the episode was complicated by Cold War politics, racism among Cuban-Americans, along with the urgent and real need for treatment among the needy, displaced population.

The book's broad temporal and conceptual scope is impressive; the long time period results in insightful conclusions about the US occupation, the Cuban Revolution, and social outcomes in both Cuba and Miami. It is further distinguished by the incorporation of sophisticated discussions of sexuality and the Cuban diaspora. 
Madhouse will be a welcome addition to work on the history of mental illness and psychiatry in Europe and the Americas; it also compliments the growing literature on the history of medicine in Latin America more broadly.

\section{REFERENCE}

LAMBE, Jennifer L.

Madhouse: psychiatry and politics in Cuban history. Chapel Hill: University of North

Carolina Press. 2017.

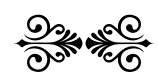

